\title{
CARACTERÍSTICAS QUANTITATIVAS E QUALITATIVAS DE CAATINGA RALEADA SOB PASTEJO DE OVINOS, SERRA TALHADA (PE) ${ }^{1}$
}

\author{
OSNIEL FARIA DE OLIVEIRA ${ }^{2 *}$, MÉRCIA VIRGINIA FERREIRA DOS SANTOS ${ }^{2,3}$, \\ MÁRCIO VIEIRA DA CUNHA ${ }^{2,3}$, ALEXANDRE CARNEIRO LEÃO DE MELLOO ${ }^{2,3}$, MÁRIO DE ANDRADE LIRA ${ }^{4,3}$, \\ GUSTAVO FERRAZ NOGUEIRA PINHEIRO DE BARROS ${ }^{2}$
}

\begin{abstract}
RESUMO - Objetivou-se estudar no período de um ano as características quantitativas e qualitativas da Caatinga raleada sob pastejo de ovinos em lotação contínua. A pesquisa consistiu em levantamento de dados da vegetação e dos ovinos em 38 hectares de Caatinga em propriedade particular. Foi avaliada a massa de forragem, composição bromatológica e botânica, solo descoberto, serrapilheira, altura média de plantas, taxa de lotação, desempenho animal e oferta de forragem. A massa de forragem variou de $422 \pm 42$ a $1.262 \pm 95 \mathrm{~kg} \mathrm{MS}^{-h^{-1}}$ no período de janeiro/2011 a janeiro/2012, com consequente variação da oferta de forragem de $13,1 \pm 1,3$ a $56,4 \pm$ $4,2 \mathrm{~kg} \mathrm{MS} . \mathrm{kg} \mathrm{PV}^{-1}$. O ganho de peso vivo dos ovinos observados foram 2,0 $22,2 \mathrm{~kg}$.cabeça ${ }^{-1}$. ciclo $^{-1}$ e $3,8 \pm 4,0$ $\mathrm{kg} \cdot \mathrm{ha}^{-1}$.ciclo ${ }^{-1}$. A serrapilheira no período seco foi maior nos meses de outubro/2011 $(38,8 \pm 4,1 \%)$ e janeiro/2012 (41,4 $\pm 4,3 \%)$. Elevados valores de solo descoberto foram observados principalmente ao longo do período seco, apresentando em média $24,4 \pm 1,5 \%$ em relação ao período total. Com o avanço do período seco os teores de MS, FDN, FDA e CHOT do pasto aumentaram, enquanto que os teores de PB, MM e CNF reduziram. A Caatinga raleada apresenta variações, ao longo do ano, na massa de forragem, composição bromatológica e desempenho animal.
\end{abstract}

Palavras-chave: Composição bromatológica. Lotação contínua. Oferta de forragem. Solo descoberto.

\section{QUANTITATIVE AND QUALITATIVE CHARACTERISTICS OF THINNED CAATINGA UNDER SHEEP GRAZING, SERRA TALHADA (PE)}

\begin{abstract}
The aim was to study during a year, the quantitative and qualitative characteristics of the thinning Caatinga grazing sheep at continuous stocking, in Serra Talhada-PE. The research consisted of data collection of vegetation and sheep, in 38 hectares of Caatinga from a private farm. We evaluated the herbage mass, herbal chemical composition, botanical composition, bare soil, litter, plants height, stocking rate, animal performance and herbage allowance. Herbage mass ranged from $422 \pm 42$ to $1262 \pm 95 \mathrm{~kg}$ DM.ha ${ }^{-1}$ within the period

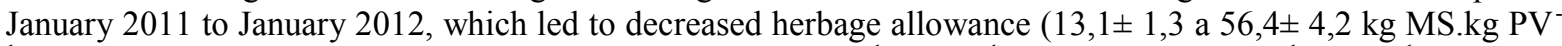
$\left.{ }^{1}\right)$. The weight gain of sheep observed was $2.0 \pm 2.2 \mathrm{~kg}$. head ${ }^{-1} \cdot$ period $^{-1}$ and $3.8 \pm 4.0 \mathrm{~kg} \cdot \mathrm{ha}^{-1} \cdot$ period $^{-1}$. The litter during the dry season was higher in October $2011(38.8 \pm 4.1 \%)$ and January $2012(41.4 \pm 4.3 \%)$. Increased values were observed on bare soil, mainly in dry season, averaging $24.4 \pm 1.5 \%$. With the advance of the dry season, the concentrations of DM, NDF, ADF and TC of pasture increased, while the $\mathrm{CP}, \mathrm{MM}$, and NFC decreased. In general, the Caatinga show varieties in the range of herbage mass, forage chemical composition, and animal performance, over the year.
\end{abstract}

Keywords: Bare soil. Chemical composition. Continuous stocking. Herbage allowance. 


\section{INTRODUÇÃO}

No semiárido brasileiro, o recurso forrageiro de maior expressão é a vegetação de Caatinga, a qual cobre cerca de $86,1 \%$ da sua área, $53 \%$ da área do Nordeste e 9,8\% do Brasil (IBGE, 2012), sendo tradicionalmente utilizado como pastagem nativa.

A região semiárida brasileira apresenta déficit hídrico (VELLOSO et al., 2002) que influencia marcadamente a oferta e a qualidade da forragem (MOREIRA et al., 2006), com os solos e a vegetação de Caatinga formando um grande mosaico dos mais variados tipos (VELLOSO et al., 2002). Nesse sentido, diversos estudos apontaram valores de massa de forragem variando de 6.454 a $378 \mathrm{~kg}$ de MS.ha ${ }^{-1}$, na qual parte deste material se encontra indisponível aos animais (MOREIRA et al., 2006; YDOYAGASANTANA et al., 2011). Naturalmente, o baixo desempenho animal tem associação positiva com a baixa produtividade e qualidade de forragem da Caatinga (ARAÚJO FILHO; CRISPIM, 2002).

Assim, objetivou-se avaliar as características do pasto (massa de forragem, altura de plantas, por- centagem de serrapilheira, porcentagem de solo descoberto e oferta de forragem) e de ovinos (peso vivo, taxa de lotação e ganho de peso) em Caatinga raleada sob pastejo, ao longo do ano, em Serra Talhada (PE).

\section{MATERIAL E MÉTODOS}

A pesquisa foi realizada durante o período de janeiro de 2011 a janeiro de 2012 na Fazenda São Miguel, em Serra Talhada (PE). O município está localizado na microrregião Pajeú, com altitude de $429 \mathrm{~m}$. O clima é do tipo Tropical Semiárido com temperatura média anual de $25,7{ }^{\circ} \mathrm{C}$ e precipitação pluvial de $696 \mathrm{~mm}$ (Figura 1). E está inserido na Depressão Sertaneja, com relevo predominantemente suave-ondulado. A predominância de solo é do tipo Luvissolos, rasos e drenados, com fertilidade natural média a alta. A vegetação é basicamente composta por Caatinga hiperxerófila, com trechos de floresta caducifólia (CPRM, 2005).

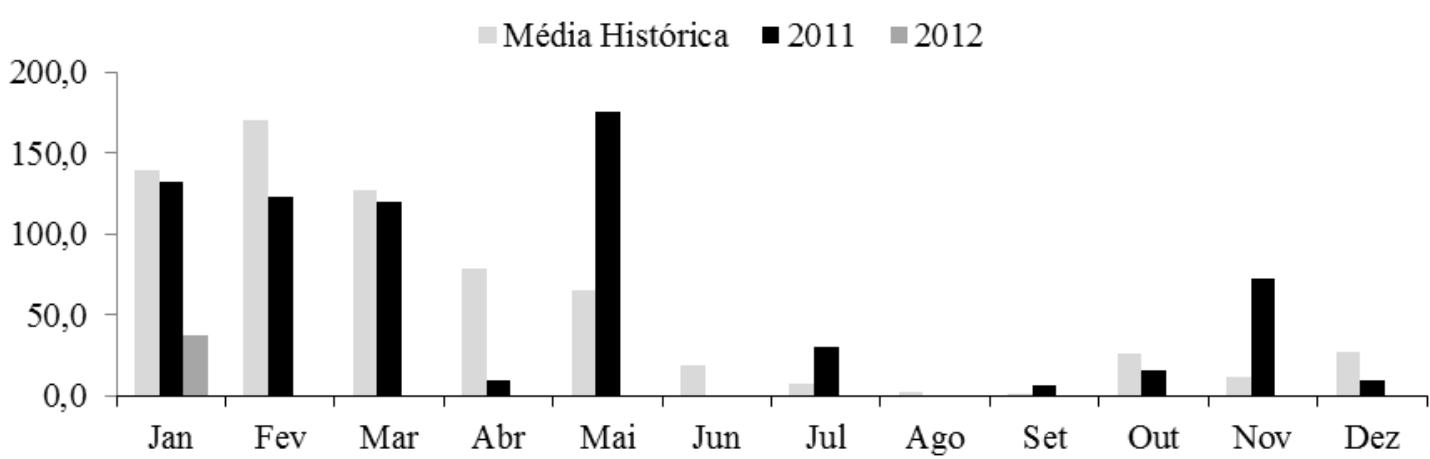

Figura 1. Precipitação pluvial $(\mathrm{mm})$ durante o período experimental e média histórica anual (2001 - 2011). Fonte: Fazenda São Miguel, Serra Talhada (PE).

A pesquisa consistiu no levantamento de dados da vegetação e dos ovinos, cuja área em estudo foi de 38 ha. Atualmente, a área é utilizada como pastagem nativa com introdução de capim-buffel (Cenchrus ciliaris L.) e capim-corrente (Uruchloa mosambicensis Hackel.) e vem sendo utilizada sob pastejo de ovinos desde 2001.

O pastejo foi realizado por 70 ovinos mestiços (Santa Inês x Dorper), machos e fêmeas, em lotação contínua, com peso vivo médio inicial de 30,9 \pm $4,4 \mathrm{~kg}$ e 10 meses de idade. Sete animais foram pesados a cada ciclo de avaliação para monitoramento do desempenho e da taxa de lotação animal (UA.ha ${ }^{-1}$, onde $1 \mathrm{UA}=97,7 \mathrm{~kg} \mathrm{PV}^{0,75}$ ). É válido ressaltar que todos os resultados relacionados ao peso vivo animal (PV) foram convertidos para peso vivo animal metabólico $\left(\mathrm{PV}^{0,75}\right)$.

No monitoramento da vegetação, a massa de forragem, altura das plantas e solo descoberto foram avaliados a cada ciclo de 56 dias. As avaliações foram realizadas ao longo de nove transectos distribuí- dos a cada $100 \mathrm{~m}$. Neles foram observados 20 pontos amostrais, cuja distância entre estes foi de $10 \mathrm{~m}$.

O método do rendimento visual comparativo, desenvolvido por Haydock e Shaw (1975), foi utilizado na estimativa da massa de forragem, utilizandose padrões de um a cinco $(1=$ menor massa; $5=$ maior massa; 2, 3 e 4 intermediários entre 1 e 5).

Para estimativa da massa de forragem, plantas herbáceas foram colhidas rente ao solo, enquanto que para as plantas arbóreo-arbustivas foram consideradas como forragem ramos com diâmetro de até $6 \mathrm{~mm}$ colhidos até $1,5 \mathrm{~m}$ de altura. $\mathrm{O}$ tamanho do quadrado utilizado para coleta foi de $1 \times 1 \mathrm{~m}$. Foram realizados 15 cortes pré-definidos (três cortes para cada padrão), além de dois cortes aleatórios por transecto para calibração das notas visuais. A partir da massa de forragem seca $\left(\mathrm{kg} \mathrm{MS} . \mathrm{ha}^{-1}\right)$ e do peso dos ovinos foi estimada a oferta de forragem, em kg MS.kg PV ${ }^{-1}$.

A composição bromatológica da forragem realizada a partir de subamostras da massa de forra- 
gem foi analisada no Laboratório de Nutrição Animal e de Forragicultura da UFRPE. Foram determinados os teores de matéria seca (MS), matéria mineral $(\mathrm{MM})$, proteína bruta $(\mathrm{PB})$ e extrato etéreo (EE), segundo metodologias descritas por Silva e Queiroz (2002). As determinações da fibra em detergente neutro (FDN) e fibra em detergente ácido (FDA) foram realizadas em aparelho autoclave, utilizandose metodologia descrita por Pell e Schofield (1993). Os teores de carboidratos totais (CHOT $=100-(\%$ $\mathrm{PB}+\% \mathrm{EE}+\% \mathrm{MM})$ ) foram estimados segundo Sniffen et al. (1992), e os teores de carboidratos nãofibrosos $(\mathrm{CNF}=100-(\% \mathrm{~PB}+\% \mathrm{FDN}+\% \mathrm{EE}+\%$ MM) obtidos conforme sugestão de Mertens (1997).

As estimativas de solo descoberto e serrapilheira (em relação a área coberta) foram realizadas visualmente, consistindo em notas variando de 0 a $100 \%$. A altura das plantas foi mensurada por meio de uma régua graduada de $2 \mathrm{~m}$ de comprimento.

As amostras de solo, coletado a diferentes profundidades ( 0 a $20 \mathrm{~cm}$ e de 20 a $40 \mathrm{~cm}$ ), foram analisadas no Laboratório de Física do Solo (análise granulométrica pelo método da pipeta (EMBRAPA, 2011)) e de Fertilidade do Solo da UFRPE. O solo foi considerado areno-siltoso, eutrófico, com acidez fraca e fertilidade média a alta $\left(\mathrm{P}=11,84 \mathrm{mg} \cdot \mathrm{dm}^{-3}\right.$; $\mathrm{Na}=0,17 \mathrm{cmol}_{\mathrm{c}} \cdot \mathrm{dm}^{-3} ; \mathrm{K}^{+}=0,21 \mathrm{cmol}_{\mathrm{c}} \cdot \mathrm{dm}^{-3} ; \mathrm{Ca}^{++}=$ $3,49 \mathrm{cmol}_{\mathrm{c}} \cdot \mathrm{dm}^{-3} ; \mathrm{Mg}^{++}=1,54 \mathrm{cmol}_{\mathrm{c}} \cdot \mathrm{dm}^{-3} ; \mathrm{Al}^{+3}=$ $0,08 \mathrm{cmol}_{\mathrm{c}} \cdot \mathrm{dm}^{-3} ; \mathrm{H}+\mathrm{Al}=3,11 \mathrm{cmol}_{\mathrm{c}} \cdot \mathrm{dm}^{-3} ; \mathrm{C} . \mathrm{O} .=$ 7,30 g. $\mathrm{kg}^{-1}$; e M.O. = 12,59 g.kg $\left.{ }^{-1}\right)($ CAVALCANTI, 1998).

Para estimativa da massa de forragem por ciclo foi obtida a equação de regressão, em que a variável independente foi o padrão e a variável dependente foi o peso, onde: $\mathrm{y}=86+280 \mathrm{x}, \mathrm{R}^{2}=0,86$ $(\mathrm{jan} / 2011) ; \mathrm{y}=41+596 \mathrm{x}, \mathrm{R}^{2}=0,93(\mathrm{mar} / 2011) ; \mathrm{y}=$ $-471+828 \mathrm{x}, \mathrm{R}^{2}=0,91(\mathrm{abr} / 2011) ; \mathrm{y}=50+370 \mathrm{x}$ (jun/2011) $\mathrm{R}^{2}=0,90 ; \mathrm{y}=-344+509 \mathrm{x}, \mathrm{R}^{2}=0,94$ $\left(\right.$ ago/2011); $\mathrm{y}=-223+549 \mathrm{x}, \mathrm{R}^{2}=0,97$ (out/2011); $\mathrm{y}$ $=231+152 \mathrm{x}, \mathrm{R}^{2}=0,93(\mathrm{dez} / 2011) ; \mathrm{y}=-142+435$ $\mathrm{x}, \mathrm{R}^{2}=0,96(\mathrm{jan} / 2012)$.

Nas demais características estudadas foram estimadas as médias e intervalos de confiança $(5 \%$ de probabilidade) utilizando-se o programa computacional GENES versão 7.0, conforme Cruz (2006).

\section{RESULTADOS E DISCUSSÃO}

A altura média das plantas arbustivo-arbóreas variou de $103,4 \pm 71,3 \mathrm{~cm}$ a $146,8 \pm 125,9 \mathrm{~cm}$. Já para as plantas herbáceas foram observadas alturas médias variando de 18,2 $\pm 23,2 \mathrm{~cm}$ a $50,7 \pm 71,2 \mathrm{~cm}$ nos períodos de avaliação (Figura 2). A altura das plantas que compõe uma pastagem é de fundamental importância na alimentação dos animais. Assim, quando o rebanho é composto por ovinos a pastagem deve ter altura de planta entre o estrato herbáceo e arbustivo, já que estes são considerados pastejadores não tão seletivos quanto os caprinos, se assemelhando aos bovinos.

O solo descoberto da pastagem foi em média $26,0 \pm 5,9 \%$, sendo maior no início do período chuvoso $(43,6 \pm 5,9 \%)$, provavelmente pelo restabelecimento das plantas em relação ao período seco antecedente. No solo descoberto, em média de 5,1 \pm $1,6 \%$ correspondeu na presença de rocha. O resultado elevado do solo descoberto no presente trabalho (Figura 2) indica que se deve permitir restabelecimento da pastagem para diminuir a exposição do solo às intempéries ambientais e ao pisoteio animal.

A presença de serrapilheira correspondeu em média a $17,7 \pm 12,5 \%$ da área de solo coberto, tendo maior contribuição $(38,8 \pm 4,1 \%$ e $41,4 \pm 4,3 \%)$ nos períodos de menor incidência de chuvas (Figura 2). O referido resultado pode ser associado ao fato das plantas da Caatinga perderem as folhas (caducifólias) para reduzirem as perdas por respiração como mecanismo de adaptação (SILVA et al., 2001).

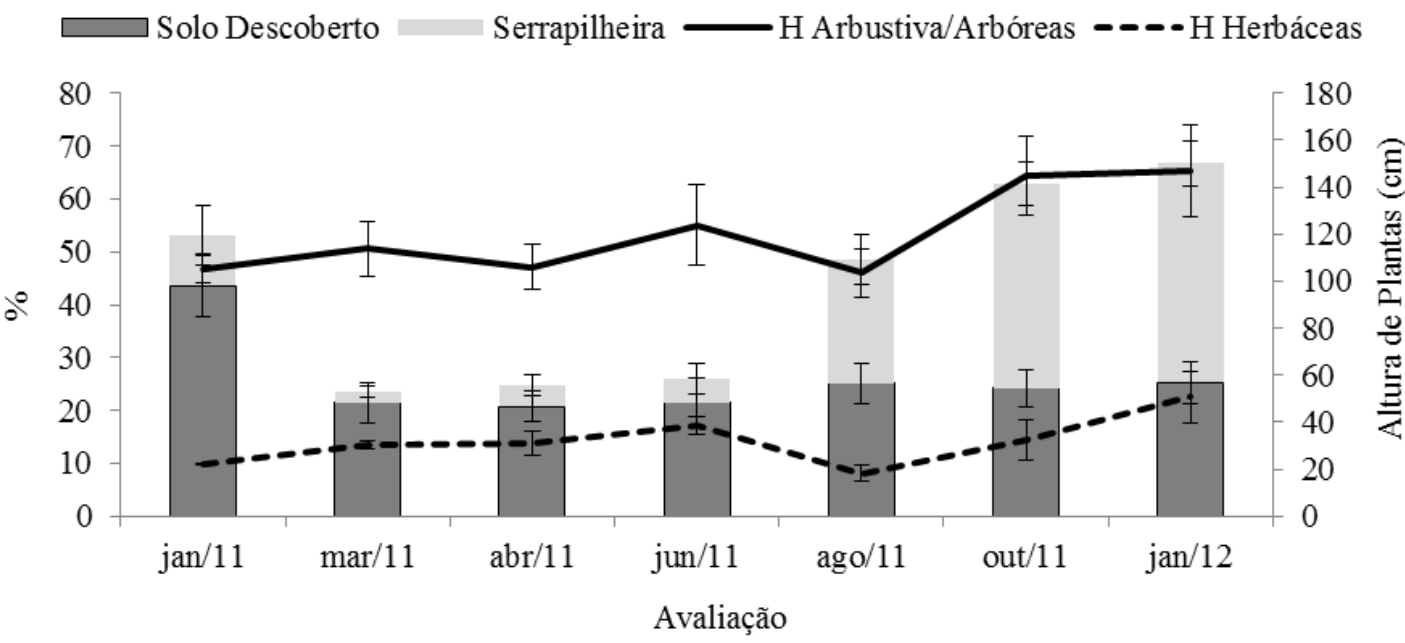

Figura 2. Solo descoberto (\%), serrapilheira (\%) e altura das plantas (cm) em Caatinga raleada sob pastejo, em diferentes períodos de avaliação, Serra Talhada (PE).

Revista Caatinga, Mossoró, v. 28, n. 3, p. 223 - 229, jul. - set., 2015 
A massa de forragem total variou de $422 \pm 42$ a $1.262 \pm 95 \mathrm{~kg} \mathrm{MS} \cdot \mathrm{ha}^{-1}$ nos meses de janeiro/2011 a janeiro/2012 (Figura 3), o que está associado principalmente pela variação ocorrida na distribuição e ocorrência de chuva. Verificou-se que a massa de forragem foi menor do que a considerada limitante (2.000 kg MS.ha ${ }^{-1}$ ) para o consumo voluntário máximo (NRC, 1987), sendo este valor obtido em pastagem cultivada e homogênea. Entretanto, neste de tipo de exploração animal o desempenho animal é mais satisfatório no fator terra, ou seja, em sistemas de latifúndio.

A massa de forragem das Dicotiledôneas foi superior às demais no período chuvoso, com valor médio de $366 \pm 155 \mathrm{~kg} \mathrm{MS} \cdot$ ha $^{-1}$ (Figura 3). Este resultado é importante, pois ovinos quando submetidos a condições adversas da composição botânica da pastagem e dependendo de suas exigências nutricionais selecionam mais as dicotiledôneas do que as Poáceas (ARAÚJO FILHO et al., 1998; SANTOS et al., 2008), apesar de suas preferências por estas (VAN SOESTt, 1994).

A massa de forragem das Poáceas foi baixa $181 \pm 43 \mathrm{~kg} \mathrm{MS} \cdot \mathrm{ha}^{-1}$, porém se manteve durante o período seco, principalmente por este componente ser formado, em sua maioria, pelo capim-buffel, que é de ciclo perene e tolerante a seca (Figura 3). Desta forma, para um bom manejo da Caatinga é necessário que se preconize espécies vegetais com boas características forrageiras, como as citadas acima, além da resistência ao pastejo e boa cobertura de solo.

A massa de forragem das Malváceas foi semelhante as das Poáceas, com valor médio de 241 $\pm 52 \mathrm{~kg} \mathrm{MS} \cdot \mathrm{ha}^{-1}$ (Figura 3) e que também se manteve durante o período seco, por serem adaptadas ao ambiente. Porém, para promover um melhor desempenho dos ovinos seria necessário o raleamento das malvas, haja vista não apresentarem bom valor forrageiro, e o capim-buffel teria maior poder de competição.

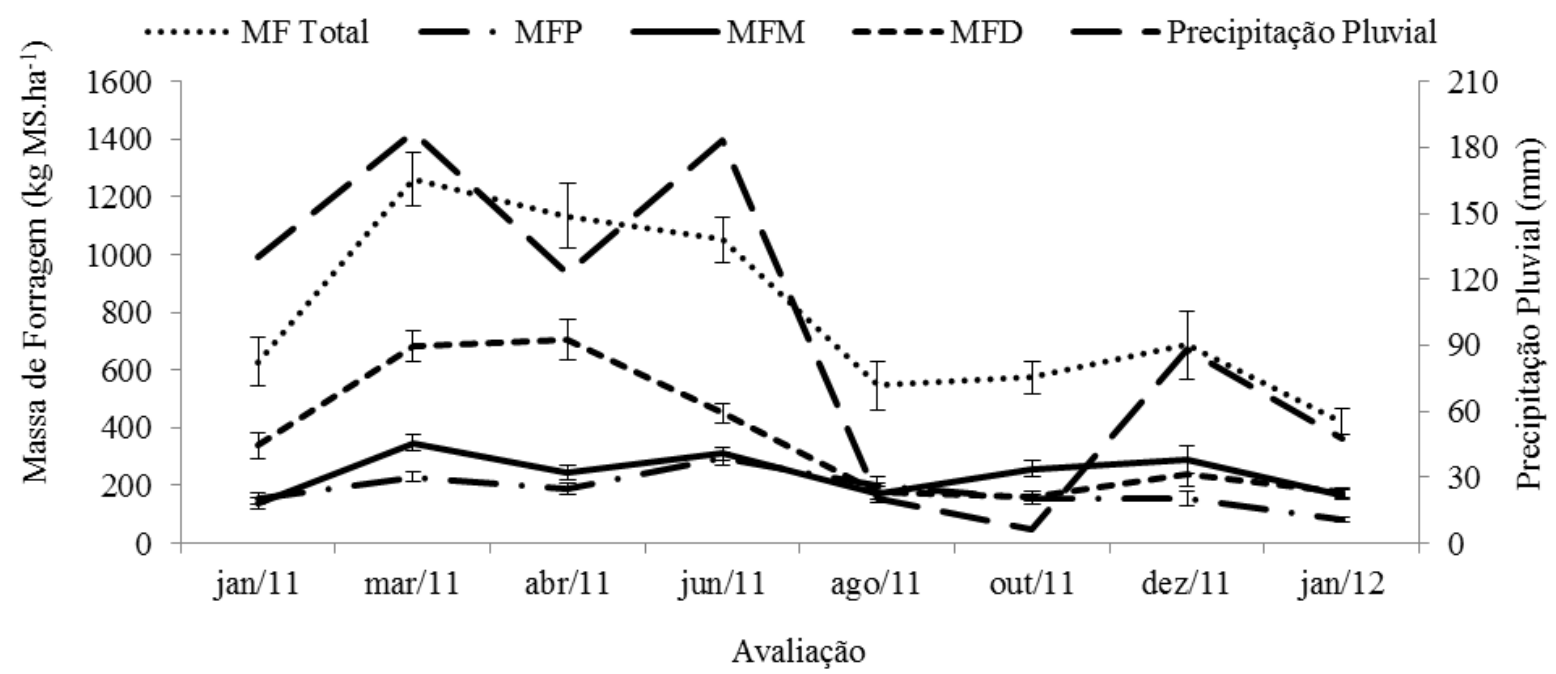

Figura 3. Massa de forragem total (MFT), Poáceas (MFP), Malváceas (MFM), Dicotiledôneas (MFD) em kg MS.ha ${ }^{-1} \mathrm{e}$ precipitação pluvial $(\mathrm{mm})$ em Caatinga raleada, em diferentes períodos de avaliação, Serra Talhada (PE).

O peso vivo médio dos animais no início da pesquisa foi de $30,9 \pm 4,4 \mathrm{~kg}$. Durante o período experimental houveram aumentos progressivos do peso até o final do período seco (Figura 4), provavelmente pelo acesso dos animais a forragem anteriormente inacessível do estrato arbustivo-arbóreo, representada pela serrapilheira (Figura 2).

A oferta de forragem variou de 13,1 $\pm 1,3$ a $56,4 \pm 4,2 \mathrm{~kg} \mathrm{MS} . \mathrm{kg} \mathrm{PV}^{-1}$, sendo consideravelmente maior que o consumo médio estimado pelo NRC (2007) para a categoria animal utilizada (2,9 kg MS.100 kg PV ${ }^{-1}$ ). Além disso, os valores também foram superiores aos estudados na literatura (4 a $20 \mathrm{~kg} \mathrm{MS.100} \mathrm{kg} \mathrm{PV}{ }^{-1}$ ) (ROMAN et al., 2007;
OLIVEIRA, 2012). Todavia, provavelmente não houve limitação do consumo pela quantidade de forragem ofertada, resultando em desempenho animal positivo (Figura 4), e a Caatinga pode se regenerar.

A taxa de lotação animal média foi de $0,28 \pm 0,03$ UA.ha $^{-1}$, cujo maior valor foi em março/2011, com $0,33 \pm 0,05$ UA.ha $^{-1}$, o que pode estar associada ao ganho de peso dos animais (Figura 4). Segundo Guimarães Filho et al. (1995), a capacidade de suporte anual da Caatinga varia de 0,07 a 0,08 UA.ha $^{-1}$ para ganhos de até $8 \mathrm{~kg}$ de PV.ha ${ }^{-1}$. Porém, os autores ora citados propõem que durante o período chuvoso a capacidade suporte pode ser em torno de 0,20 a 0,25 UA.ha $^{-1}$. 


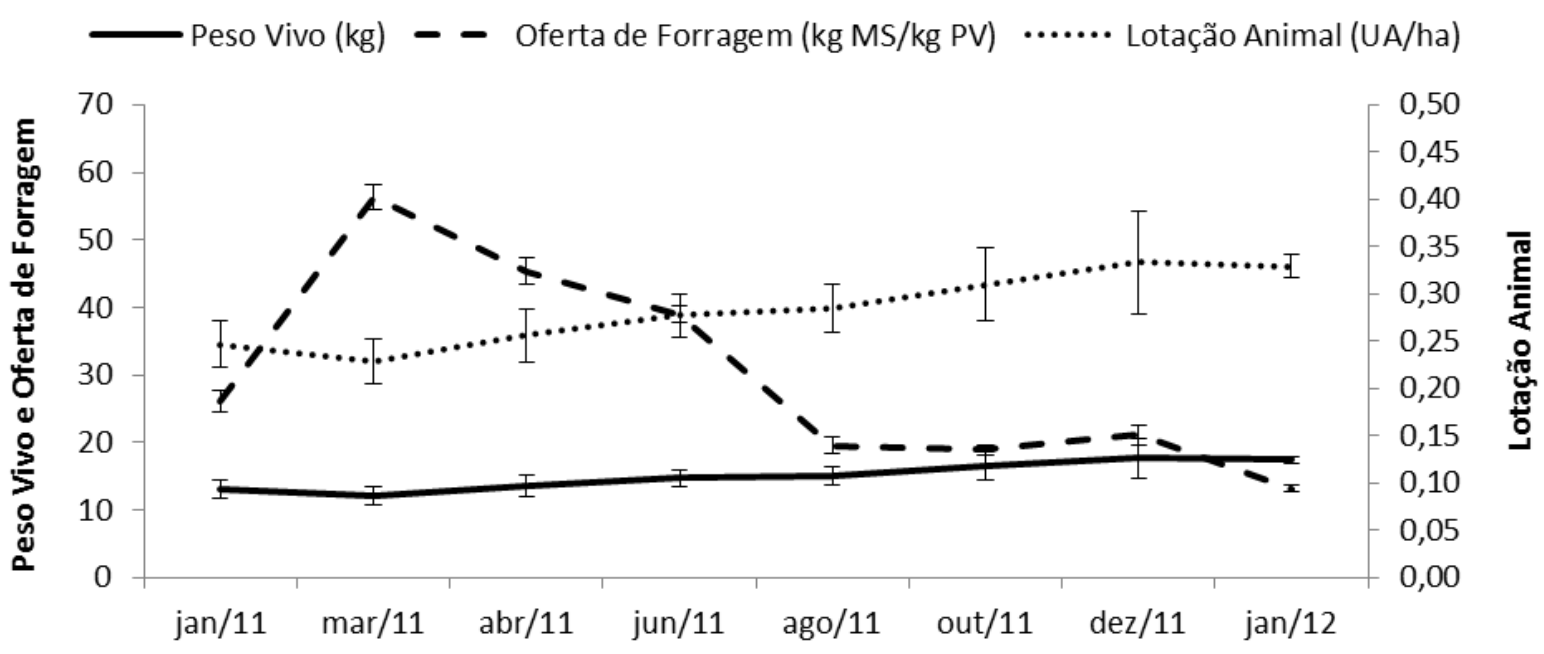

\section{Avaliações}

Figura 4. Oferta de forragem, peso vivo e taxa de lotação animal em área de Caatinga raleada sob pastejo, em diferentes períodos de avaliação, Serra Talhada (PE).

Na composição bromatológica (Tabela 1) fora observado que o teor de MS do pasto aumentou com a redução da precipitação pluvial (Figura 1). Os teores médios de FDN e FDA do pasto foram de 62,3\% e $35,4 \%$, respectivamente. Naturalmente com o avanço do período seco, o teor de FDN e FDA das plantas aumentaram devido a formação de novas paredes celulares e espessamento das demais (MERTENS, 1993). Entretanto, quando ocorreu precipitação pluvial em novembro/2011 e janeiro/2012 (Figura 1), os teores de FDN e FDA observados nas plantas reduziram. Os teores médios de CHOT $(80,1 \%)$ e CNF $(17,8 \%)$ tiveram relações positivas e negativas, respectivamente, com o resultado de FDN e FDA (Tabela 1). Os respectivos resultados se aproximam dos encontrados por Ydoyaga-Santana et al. (2011), que foram de 57\% de FDN e 45\% de FDA, e pelos observados por Moreira et al. (2006), que fo- ram de 53,0\% de FDN e 39,9\% de FDA, cujas pesquisas foram realizadas no período chuvoso.

Em relação ao teor de $\mathrm{PB}$ do pasto (Tabela 1), o valor em média foi elevado $(8,8 \pm 0,5 \%)$ se considerarmos a maioria das forrageiras tropicais em condições naturais, sendo ainda superiores aos limites de $7 \%$ para o bom funcionamento da fermentação ruminal (VAN SOEST, 1994), exceto em outubro/2011 $(3,6 \pm 0,4 \%)$. Provavelmente, os valores reduzidos de proteína podem estar associados à presença de espécies de baixo valor forrageiro. Vale ressaltar que parte desta proteína pode estar ligada a fibra, conforme observado por Moreira et al. (2006) e Santos et al. (2009). A proporção que a precipitação de chuva vai diminuindo o teor de proteína bruta e carboidratos não fibrosos das forragens vão decrescendo e o teor de fibra aumentando (TOMICH et al., 2002).

Tabela 1. Composição bromatológica da forragem em Caatinga raleada pastejada por ovinos, em diferentes períodos de avaliação, Serra Talhada (PE).

\begin{tabular}{|c|c|c|c|c|c|c|c|c|}
\hline Ciclos & MS & MM & FDN & FDA & $\mathrm{EE}$ & $\mathrm{PB}$ & $\mathrm{CNF}$ & $\mathrm{CHOT}$ \\
\hline & & & & \multicolumn{5}{|c|}{$\%$} \\
\hline $\mathrm{Jan} / 11$ & $32,3 \pm 2,2$ & $10,7 \pm 1,0$ & $48,3 \pm 2,0$ & $23,8 \pm 1,3$ & $2,2 \pm 0,2$ & $12,9 \pm 0,8$ & $25,9 \pm 1,5$ & $74,2 \pm 1,5$ \\
\hline Mar/11 & $30,5 \pm 1,4$ & $8,8 \pm 0,5$ & $56,8 \pm 3,1$ & $33,0 \pm 1,8$ & $2,6 \pm 0,4$ & $9,1 \pm 0,9$ & $22,6 \pm 2,1$ & $79,4 \pm 1,2$ \\
\hline $\mathrm{Abr} / 11$ & $30,5 \pm 1,1$ & $8,5 \pm 0,6$ & $60,3 \pm 2,0$ & $35,4 \pm 1,4$ & $2,3 \pm 0,2$ & $7,3 \pm 1,0$ & $21,6 \pm 2,2$ & $81,9 \pm 1,2$ \\
\hline Jun/11 & $34,5 \pm 1,4$ & $11,4 \pm 0,9$ & $67,6 \pm 3,8$ & $39,2 \pm 2,4$ & $2,6 \pm 0,5$ & $8,9 \pm 1,0$ & $9,4 \pm 3,1$ & $77,0 \pm 1,4$ \\
\hline Ago/11 & $57,9 \pm 2,5$ & $8,1 \pm 0,9$ & $72,2 \pm 3,6$ & $42,0 \pm 2,4$ & $2,5 \pm 0,2$ & $6,7 \pm 0,7$ & $10,4 \pm 3,3$ & $82,6 \pm 1,2$ \\
\hline Out/11 & $78,9 \pm 1,3$ & $5,9 \pm 0,6$ & $79,2 \pm 1,6$ & $48,5 \pm 1,7$ & $1,2 \pm 0,1$ & $3,6 \pm 0,4$ & $10,1 \pm 1,6$ & $89,3 \pm 0,7$ \\
\hline Dez/11 & $48,8 \pm 2,4$ & $10,1 \pm 0,4$ & $58,5 \pm 2,9$ & $28,7 \pm 2,1$ & $1,8 \pm 0,1$ & $10,6 \pm 1,0$ & $18,9 \pm 3,1$ & $77,5 \pm 1,0$ \\
\hline $\mathrm{Jan} / 12$ & $73,8 \pm 4,5$ & $6,8 \pm 0,6$ & $55,7 \pm 4,0$ & $32,7 \pm 3,2$ & $3,0 \pm 0,6$ & $11,2 \pm 1,2$ & $23,3 \pm 3,9$ & $79,0 \pm 1,3$ \\
\hline
\end{tabular}

Quanto ao desempenho animal, os ganhos de peso vivo foram de $51 \mathrm{~g} \cdot \mathrm{animal}^{-1} \cdot \mathrm{dia}^{-1}$ e $9,4 \mathrm{~kg} \cdot \mathrm{ha}^{-1}$ no período chuvoso e de 32 g.animal ${ }^{-1} \cdot$ dia $^{-1}$ e 14,2 $\mathrm{kg} \cdot \mathrm{ha}^{-1}$ no período seco. Naturalmente, como o perío- do seco foi mais prolongado houve menor ganho de peso diário em relação ao período chuvoso. Quanto aos ciclos avaliados, os animais obtiveram uma produtividade média de 2,0 $\pm 2,2 \mathrm{~kg}$.animal ${ }^{-1} \cdot \operatorname{ciclo}^{-1} \mathrm{e}$ 
$3,8 \pm 4,0 \mathrm{~kg} \cdot \mathrm{ha}^{-1} \cdot$ ciclo $^{-1}$, respectivamente (Figura 5). Araújo Filho et al. (1998) estudaram o ganho de peso de ovinos e obtiveram $8,1 \mathrm{~kg} \cdot$ cabeça $^{-1}$ e $10,2 \mathrm{~kg} \cdot \mathrm{ha}^{-1}$ durante a período seco, em Caatinga sob pastejo. Araújo Filho e Crispim (2002) informaram que a produtividade de ovinos em Caatinga nativa deve ser acima de 31 g.cabeça ${ }^{-1} \cdot$ dia $^{-1}$, em pastejo solteiro. Vale ressaltar que os dados de desempenho animal podem ser relacionados à composição botânica da pastagem e a massa de forragem presente, cujo aspectos variam conforme o tipo de Caatinga e ações antrópicas.

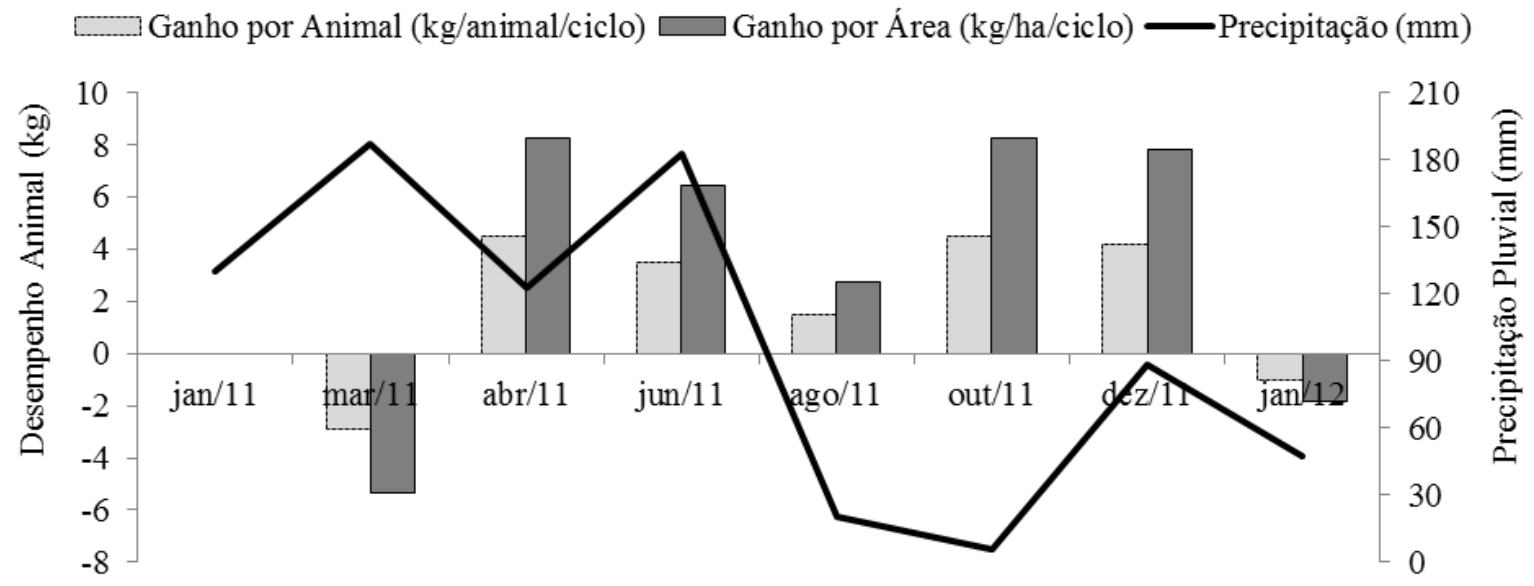

Avaliação

Figura 5. Desempenho animal (kg.animal ${ }^{-1} \cdot \operatorname{ciclo}^{-1}$ e kg.ha $\left.{ }^{-1} \cdot \operatorname{ciclo}^{-1}\right)$ e precipitação pluvial $(\mathrm{mm})$ em área de Caatinga raleada pastejada por ovinos, em diferentes períodos de avaliação, Serra Talhada (PE).

\section{CONCLUSÃO}

A Caatinga estudada apresenta solo descoberto e serrapilheira principalmente no período seco do ano. A massa de forragem reduz com o avanço do período seco, porém o desempenho animal é positivo devido a oferta de forragem ter sido além da necessidade destes.

Considerando as características quantitativas e qualitativas, a Caatinga estudada oferece condições para o pastejo de ovinos, principalmente durante o período chuvoso. Nos primeiros meses do período seco a Caatinga também permite ganho de peso animal. Porém, são necessários manejos estratégicos que favoreçam a presença de plantas de valor forrageiro e que a taxa de lotação animal utilizada considere as variações da oferta e qualidade da forragem para a busca da sustentabilidade na pecuária em área de Caatinga.

\section{REFERÊNCIAS}

ARAÚJo FILHO, J. A.; CRISPIM, S. M. A. Pastoreio combinado de bovinos, caprinos e ovinos em áreas de caatinga no nordeste do Brasil. In: $\mathrm{CON}$ FERÊNCIA VIRTUAL GLOBAL SOBRE PRODUÇÃO ORGÂNICA DE BOVINOS DE CORTE, 1, 2002, [s. 1.]. Disponível em: http:// www.cpap.embrapa.br/agencia/congressovirtual/pdf/ portugues/03pt08.pdf, Acesso em: 18/05/2012.

ARAÚJO FILHO, J. A; LEITE, E. R.; SILVA, N. L.
Contribution of woody species to the diet composition of goat and sheep in Caatinga vegetation. Pasturas Tropicales, Colombia, v. 20, n. 2, p. 41-45, 1998.

CAVALCANTI, F. J. A. C. Recomendação de adubação para o estado de Pernambuco: $2^{\text {a }}$ aproximação, $2^{\mathrm{a}}$ Revisão. Recife: IPA, EMBRAPA, UFRPE, UFPE, EMATER, 1998, 198 p.

CPRM - Serviço Geológico do Brasil. 2005. Diagnóstico do Município de Serra Talhada - PE. Ministério de Minas e Energia: Secretaria de Geologia, Mineração e Transformação Mineral. Recife - PE, 22 p. Disponível em: http://www.cprm.gov.br/rehi/ atlas/pernambuco/ relatorios/SETA148.pdf. Acesso em: 25/09/2011.

CRUZ, C. D. Programa Genes: Biometria. Editora UFV. Viçosa, MG, 2006, 382 p.

EMBRAPA. Centro Nacional de Pesquisa de Solos. Manual de métodos de análise de solos / organizadores, Guilherme Kangussú Donagema... [et al.]. Dados eletrônicos — Rio de Janeiro: Embrapa Solos, 2011. 230 p. - (Documentos / Embrapa Solos, 132).

GUIMARÃES FILHO, C.; SOARES, J. G. G.; RICHÉ, G. R. Sistema caatinga-buffel-leucena para produção de bovinos no semi-árido. Petrolina: Embrapa-CPATSA, 1995. 39 p. (EmbrapaCPATSA. Circular Técnica, 34).

HAYDOCK, K. P.; SHAW, N. H. The comparative 
yield method for estimating dry matter yield of pasture. Australian Journal of Experimental Agriculture and Animal Husbandry, Melbourne, v. 15, n. 76, p. 663-670, 1975.

IBGE. Mapa de Biomas e de Vegetação 2012. Disponível em: http://www.ibge.gov.br/home/ geociencias/default_prod.shtm\#MAPAS. Acesso em: $08 / 05 / 2012$.

MERTENS, D. R. Creating a system for meeting the fiber requirements of dairy cows. Journal of Dairy Science, Champaign, v. 80, n. 7, p. 1463-1481, 1997.

MERTENS, D. R. Kinetics of cell wall digestion and passage in ruminant. In: JUNG, H. G. et al. (Ed.). Forage cell wall structure and digestibility. Madison: America Society of Agronomy; Crop Science Society of America; Soil Science Society America, p. 535-570, 1993.

MOREIRA, J. N. et al. Caracterização da vegetação e da dieta de ovinos em área de caatinga no sertão de Pernambuco. Pesquisa Agropecuária Brasileira, Brasília, v. 41, n. 11, p. 1643-1651, 2006.

NRC. Predicting feed intake of food-producing animals. National Academy Press, Washington, DC, 1987.

NRC. Nutrient requirements of small ruminants: Sheep, goats, cervids, and new world camelids. Washington, D.C.: National Academy Press, 2007. 384 p.

OLIVEIRA, R. G. Características produtivas e qualitativas dos pastos e desempenho produtivo de ovinos criados em pastagens de capim-bufel com diferentes ofertas de forragem. 2012. $68 \mathrm{f}$. Dissertação (Mestrado em Ciência Animal: Área de Concentração em Forragicultura) - Universidade Federal do Vale do São Francisco, Petrolina, 2012.

PELL, A. N.; SCHOFIELD, P. Computerized monitoring of gas production to measure forage digestion in vitro. Journal of Dairy Science, Champaign, v. 76, n. 9, p. 1063-1073, 1993.

ROMAN, J. et al. Comportamento ingestivo e desempenho de ovinos em pastagem de azevém anual (Lolium multiflorum Lam.) com diferentes massas de forragem. Revista Brasileira de Zootecnia, Viçosa v. 36, n. 4, p. 780-788, 2007.

SANTOS, G. R. A. et al. Composição química e degradabilidade in situ da ração em ovinos em área de Caatinga no sertão de Pernambuco. Revista Brasileira de Zootecnia, Viçosa, v. 38, n. 2, p. 384-391, 2009.
SANTOS, G. R. A. et al. Determinação da composição botânica da dieta de ovinos em pastejo na Caatinga. Revista Brasileira de Zootecnia, Viçosa, v. 37, n. 10, p. 1876-1883, 2008.

SILVA, D. J.; QUEIROZ, A. C. Análise de alimentos: métodos químicos e biológicos. Viçosa, MG, UFV, 2002. 235 p.

SILVA, V. M. et al. Desempenho de bovinos e da pastagem em diferentes níveis de manipulação da caatinga. Pesquisa Agropecuária Pernambucana, Recife, v. 12, n. especial, p. 99-107, 2001.

SNIFFEN, C. J. et al. A net carbohydrate and protein system for evaluating cattle diets: II. Carbohydrate and protein availability. Journal of Animal Science, Champaign, v. 70, p. 3562-3577, 1992.

TOMICH, T. R. et al. Suplementação com mistura múltipla contendo uréia como fonte de nitrogênio para bovinos em pastagens de braquiária no período das águas. In: REUNIÃO ANUAL DA SOCIEDADE BRASILEIRA DE ZOOTECNIA, 39. 2002., Recife. Anais... Recife: UFRPE, 2002. 1 CD-ROM.

VAN SOEST, P. J. Nutritional ecology of the ruminant. 2. ed. Ithaca: Comstock, 1994. 476 p.

VELLOSO, A. L.; SAMPAIO, E. V. S. B.; PAREYN, F. G. C. Ecorregiões propostas para o bioma caatinga. Recife: Associação Plantas do Nordeste; Instituto de Conservação Ambiental, The Nature Conservancy do Brasil, 2002. 76 p.

YDOYAGA-SANTANA, D.F. et al. Caracterização da caatinga e da dieta de novilhos fistulados, na época chuvosa, no semiárido de Pernambuco. Revista Brasileira de Zootecnia, Viçosa, v. 40, n. 1, p. 69-78, 2011. 